\title{
Uma Abordagem para Gerência Estratégica de Portfólio com Foco na Seleção de Projetos
}

\author{
Adler Diniz de Souza ${ }^{1,2}$, Ana Regina Rocha ${ }^{1}$, Gleison Santos ${ }^{1}$, Tiago \\ Vinícius Paiva do Carmo ${ }^{2}$, Douglas Batista Alexandre ${ }^{2}$ \\ ${ }^{1}$ COPPE/UFRJ - Universidade Federal do Rio de Janeiro \\ Programa de Engenharia de Sistemas e Computação \\ Av. Horácio Macedo, 2030, Prédio do Centro de Tec., Bloco H, Sala 319 \\ Caixa Postal 68511 - CEP 21941-914 - Rio de Janeiro, RJ \\ ${ }^{2}$ SWFactory Consultoria e Sistemas LTDA. \\ Rua Santana, 179 salas 306 e 308 - Centro \\ CEP 37200-000 - Lavras, MG \\ \{adler, tvinicius, douglas\}@swfactory.com.br \\ \{darocha, gleison\}@cos.ufrj.br
}

Resumo: A fim de buscar o aumento da taxa de sucesso dos projetos e o aumento da eficácia do gerenciamento, é necessário promover o alinhamento estratégico dos projetos aos interesses da organização. Isto pode ser alcançado com uma adequada gestão da carteira (portfólio) de projetos de forma a maximizar os benefícios $e$ minimizar os riscos decorrentes da execução dos projetos. Este trabalho apresenta um processo para apoiar a gerência estratégica de portfólio, por meio da identificação das regras de governança do portfólio, identificação e categorização dos projetos, seleção, priorização e balanceamento do portfólio, manutenção do pipeline e encerramento dos projetos. O processo foi construído com base nas melhores práticas de gerência de projetos, programa e portfólio encontradas na literatura e está aderente ao processo de gerência de portfólio de projetos da norma ISO/IEC 12207:2008.

\section{Introdução}

Independente do entusiasmo, determinação e esforço dos executivos durante a elaboração do planejamento estratégico, os objetivos nele definidos freqüentemente não serão alcançados por diversas razões, que vão desde a falta de entendimento, de orçamento, de recursos, de competências e até de mudanças em fatores externos. É possível encontrar dentro de diversas organizações projetos que foram propostos, aprovados e que não atingiram os benefícios prometidos. Exemplos comuns são projetos inadequados, não sincronizados com os objetivos da organização, com riscos excessivos ou aprovados em decorrência de força política dos patrocinadores. Esses projetos drenam recursos escassos que poderiam ser direcionados a projetos capazes de trazer mais benefícios para as organizações (YELIN, 2007). 
Muitas empresas empenham grande esforço concentradas em fazer os projetos darem certo e se esquecem de gastar tempo selecionando os projetos certos. Uma das maneiras de evitar tais problemas é promovendo a seleção adequada dos projetos candidatos a compor o portfólio, de forma a garantir que eles sejam os mais aptos a atender aos objetivos e metas organizacionais. Desta forma, o problema de gerência de portfólio de uma organização pode ser divido em dois: (i) selecionar os projetos adequados para a execução e separá-los dos que não são adequados e (ii) manter a execução dos projetos que permanecem atendendo a seus interesses.

Esse artigo apresenta um processo para gerência de portfólio que utiliza diversas técnicas e ferramentas para seleção de projetos por meio da avaliação de seus benefícios, riscos, alinhamento estratégico e balanceamento. $\mathrm{O}$ artigo está organizado da seguinte maneira: a segunda seção apresenta uma revisão da literatura sobre gerência de portfólio e planejamento estratégico, a terceira descreve o processo para gerenciamento de portfólio e, por fim, a quarta seção apresenta as conclusões e perspectivas futuras de trabalho.

\section{Planejamento Estratégico e Gerência de Portfólio}

Esta seção apresenta diversos conceitos sobre gerência de portfólio e projetos e a relação entre a estratégia organizacional e a gerência de portfólio.

\subsection{Projetos e gerência de projetos}

Várias são as definições de projetos que podem ser encontradas na literatura. CRAWFORD et al. (2002) definem projeto como um complexo e não-rotineiro esforço único limitado por tempo, orçamento, recursos e especificações de desempenho para atender a um objetivo ou meta definidos pelo cliente. Segundo a NBR-ISO1006 (2000), projeto é um processo único, consistindo de um grupo de atividades coordenadas e controladas com datas para início e término, empreendido para alcance de um objetivo, conforme requisitos específicos, incluindo limitações de tempo, custo e recursos.

Executar um projeto envolve fazer algo que não foi feito antes, significa gerar produtos, serviços ou mesmo resultados exclusivos e únicos com o intuito de atender um ou mais objetivos. Esses objetivos podem ser internos ou externos à organização e devem estar alinhados às estratégias dessa organização.

$\mathrm{O}$ fato de um projeto existir com o intuito de atender a objetivos ou metas permite que ele seja utilizado como um mecanismo para operacionalização do planejamento estratégico organizacional. Entretanto, o alcance desses objetivos e metas está intimamente ligado à gerência adequada do projeto. A seguir, serão apresentadas algumas definições do que é gerência de projetos:

- Gerência de projetos é o planejamento, programação e controle de uma série de tarefas integradas de forma a atingir, com êxito, os objetivos do projeto, para benefício dos envolvidos (KERZNER, 2005). 
- O PMI (2004) define gerência de projetos como sendo a aplicação de conhecimentos, habilidades, ferramentas e técnicas nas atividades do projeto com o objetivo de atender as suas necessidades.

Os projetos representam um meio de organizar atividades que não podem ser abordadas dentro dos limites operacionais normais da organização. São, portanto, freqüentemente utilizados como um meio para atingir os objetivos definidos no plano estratégico de uma organização, seja a equipe do projeto formada por funcionários da organização ou por um prestador de serviços contratado (PMI, 2004). Em um cenário ideal onde a empresa tenha recursos para executar todos os projetos candidatos a atender um determinado conjunto de metas e objetivos, todos eles seriam atendidos. Entretanto, esta não é a realidade da grande maioria das empresas e a execução dos projetos é limitada por questões relacionadas a tempo, orçamento e recursos, entre outras restrições, forçando-as a limitar também o número de projetos executados ao mesmo tempo, como mostra a Figura 1. Assim, um novo desafio tem surgido para as organizações: avaliar, priorizar e selecionar os projetos candidatos a atender determinados objetivos de forma alinhada à estratégia organizacional, ligando às atividades estratégicas, táticas e operacionais (YELIN, 2006).

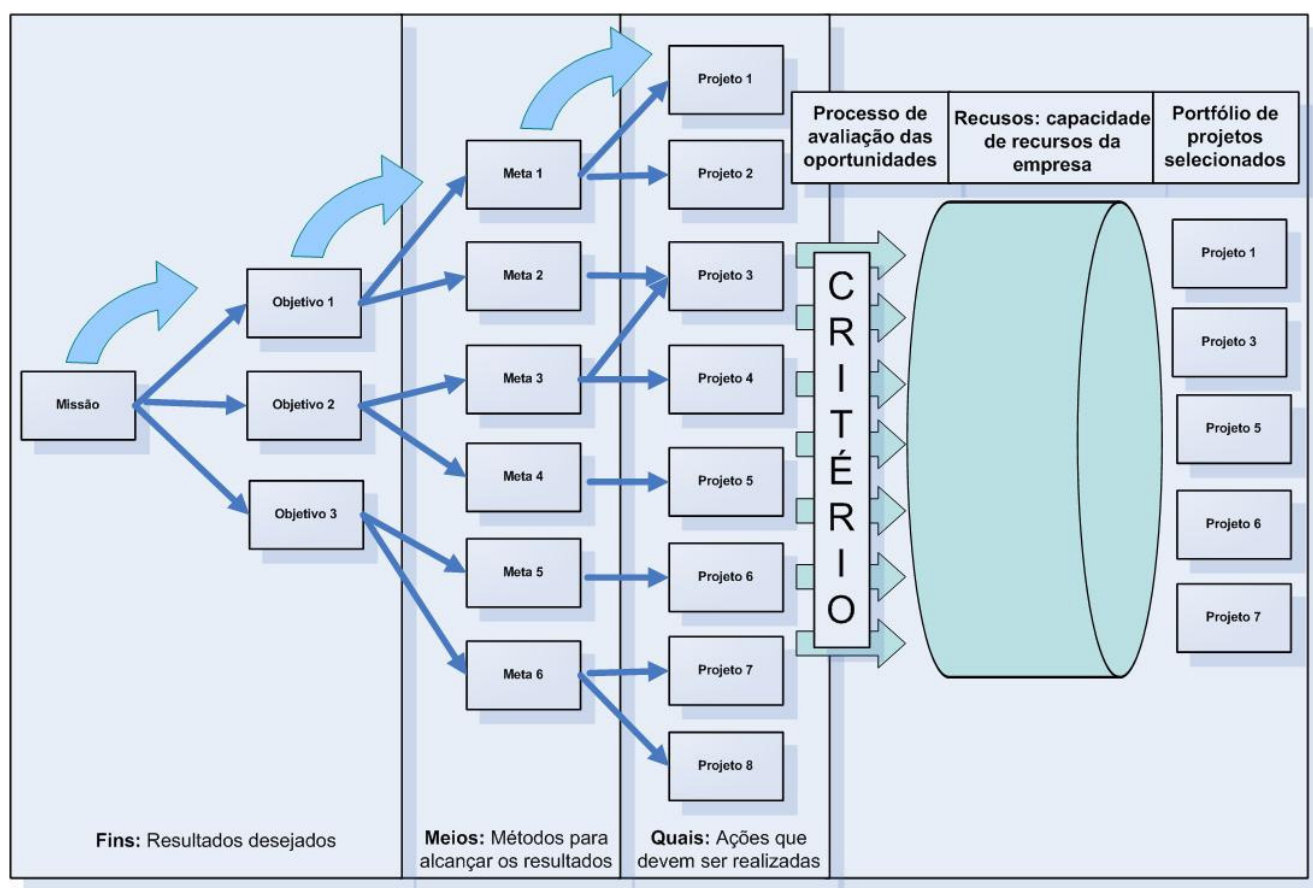

Figura 1 - Realização dos objetivos e metas por meio de projetos. Adaptado de (YELIN, 2006)

\subsection{Portfólio e gerência de portfólio}

A estratégia de negócio pode ser alcançada ou relacionada à gerência de portfólio pela seleção dos projetos adequados dentro do processo de alinhamento estratégico (SRIVANNABOON, 2006). Estudos sobre seleção e priorização de projetos como meio de obter o alinhamento estratégico são encontrados em (COOPER et al., 1998) e estudos sobre o balanceamento de projetos em (N. ARCHER, 1999) e (COOPER et al., 2000). 
Segundo o PMI (2006a), portfólio é uma coleção de projetos, programas, portfólios e outros trabalhos que são agrupados para facilitar a gerência efetiva do trabalho e o alcance dos objetivos estratégicos de negócio. A gerência de portfólio é a gerência centralizada de um ou mais portfólios. Esta gerência inclui a identificação, categorização, avaliação, seleção, priorização, autorização, gerência e controle dos projetos, programas e outros trabalhos relacionados com base no alinhamento e contribuição aos objetivos e estratégias da organização (PMI, 2006a), conforme ilustra a Figura 2.

Na Figura 2, cada caixa representa um processo do padrão de gerência de portfólio do PMI (2006a). As linhas horizontais representam os diversos níveis hierárquicos de uma empresa e os respectivos processos que são executados por cada um desses níveis hierárquicos. Os padrões do PMI definem os processos das linhas correspondentes à gerência de portfólio (PMI, 2006a), programas (PMI, 2006b) e projetos (PMI, 2004). Os processos da linha de gerência de portfólio fornecem ferramentas e técnicas que permitem a identificação, categorização, avaliação, seleção e priorização dos projetos candidatos a compor o portfólio, fornecendo assim um mecanismo de seleção dos projetos que mais contribuem para o alcance dos objetivos estratégicos. Também fornecem processos que tratam do monitoramento e controle dos projetos que fazem parte de seu portfólio, decidindo quais projetos devem continuar e quais projetos devem deixar o portfólio.

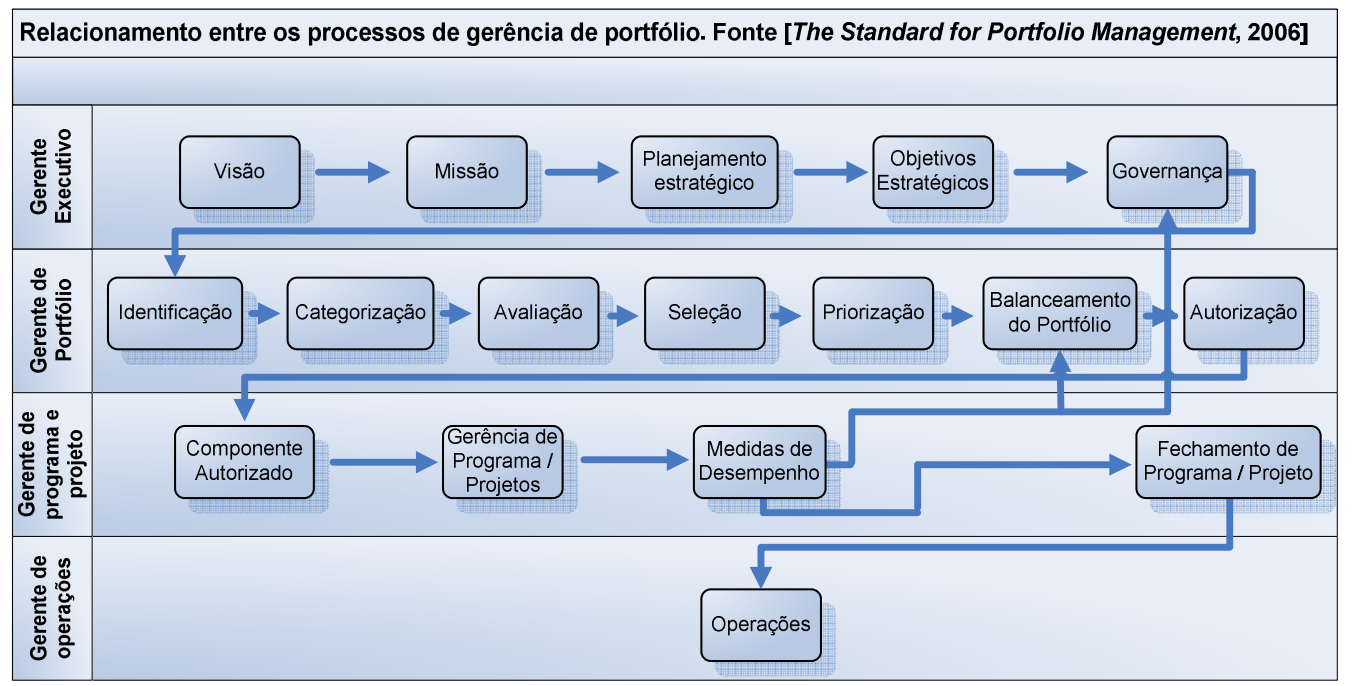

Figura 2 - Relacionamento entre os processos de gerência de portfólio (PMI, 2006a)

\section{Processo para Gerência de Portfólio}

Essa seção descreve o processo proposto para a gerência de portfólio, dando ênfase aos subprocessos que antecedem a aprovação dos projetos, ou seja, os subprocessos "Definir Gerência Estratégica de Portfólio", "Identificar e Categorizar Projetos" e "Selecionar os Projetos" (Decisões táticas de portfólio).

Foi construída uma ferramenta integrada na Estação Taba de forma apoiar a execução do processo definido pelas organizações. A Estação Taba 
(MONTONI et al. 2007) é composta por um conjunto de ambientes e ferramentas que auxiliam os engenheiros de software na definição, execução, avaliação e melhoria dos processos de desenvolvimento e manutenção. As ferramentas disponíveis, atualmente, apóiam os níveis G, F, E, D e C do MRMPS (SOFTEX, 2007) e os níveis equivalentes do CMMI (SEI, 2006). Com a evolução do MR-MPS para englobar também o processo de Gerência de Portfólio de Projetos, a definição dessa ferramenta na Estação Taba também aumenta a sua possibilidade de uso pelas organizações brasileiras.

\subsection{Visão geral do processo}

O processo proposto é composto por 5 subprocessos: (i) Definir Gerência Estratégica de Portfólio, (ii) Identificar e Categorizar Projetos, (iii) Selecionar dos Projetos, (iv) Manter Pipeline e (v) Entregar benefícios, conforme pode ser visto na Figura 3. Este processo está compatível com o processo de gerência de portfólio da norma internacional ISO/IEC 12207:2008 (ISO/IEC12207, 2008).

\section{Visão Geral do Processo de Gerência de Portfólio}

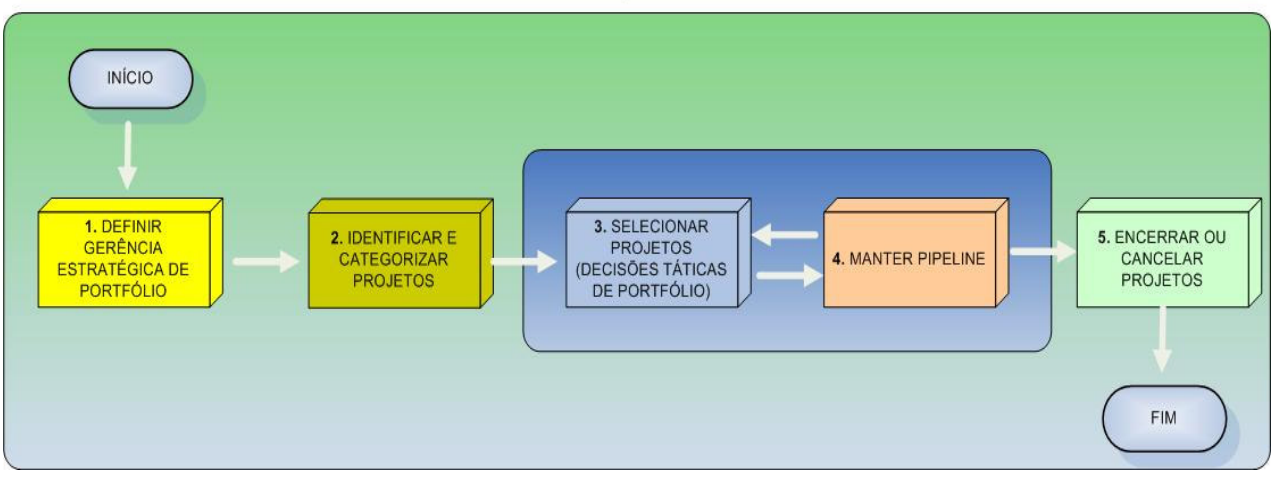

Figura 3 - Visão geral do processo para gerência de portfólio

Por serem o foco deste trabalho, os três primeiros subprocessos são descritos a seguir de maneira detalhada; os demais subprocessos serão descritos brevemente. Para cada subprocesso, serão apresentados seu propósito, seus principais objetivos, os resultados esperados com sua execução e as atividades necessárias para atender aos resultados esperados.

\section{- Primeiro subprocesso: "Definir gerência estratégica de portfólio"}

O propósito deste subprocesso é estabelecer critérios claros de governança do portfólio (a estratégia da organização) a fim de facilitar a seleção, priorização e balanceamento dos projetos candidatos a compor o portfólio da organização. Este subprocesso será executado em duas situações: i) quando o portfólio é criado e sua estratégia de gerência é estabelecida; ou ii) quando alguma estratégia for alterada e parte das regras de governança do portfólio devem ser revistas.

Os principais objetivos deste subprocesso são: (i) identificar e registrar áreas e subáreas de investimentos para posterior categorização e balanceamentos dos investimentos; (ii) registrar objetivos e metas estratégicas 
do planejamento estratégico; (iii) identificar e registrar categorias e benefícios padrão para posterior avaliação, classificação e alinhamento estratégico; (iv) parametrizar Score $\operatorname{Card}^{1}$ (SC) para seleção de projetos (decisões estratégicas de Portfólio) e SC para os indicadores de gerência de projetos, e (v) parametrizar quadrantes dos gráficos de benefícios e riscos ${ }^{2}$ para posterior seleção dos projetos. Para isso, o subprocesso foi dividido em quatro atividades que visam à obtenção desses objetivos:

- Atividade 1: Definir mapa estratégico.

O principal objetivo desta atividade é a definição do mapa de investimento desejado para a organização, indicando em que áreas e subáreas os investimentos devem ser segmentados e em quais proporções. Um Mapa de investimento estratégico desejado é exibido na Figura 4, este mapa será utilizado, posteriormente, no subprocesso "Selecionar projetos (Decisões táticas de portfólio)", na atividade de balanceamento do portfólio.

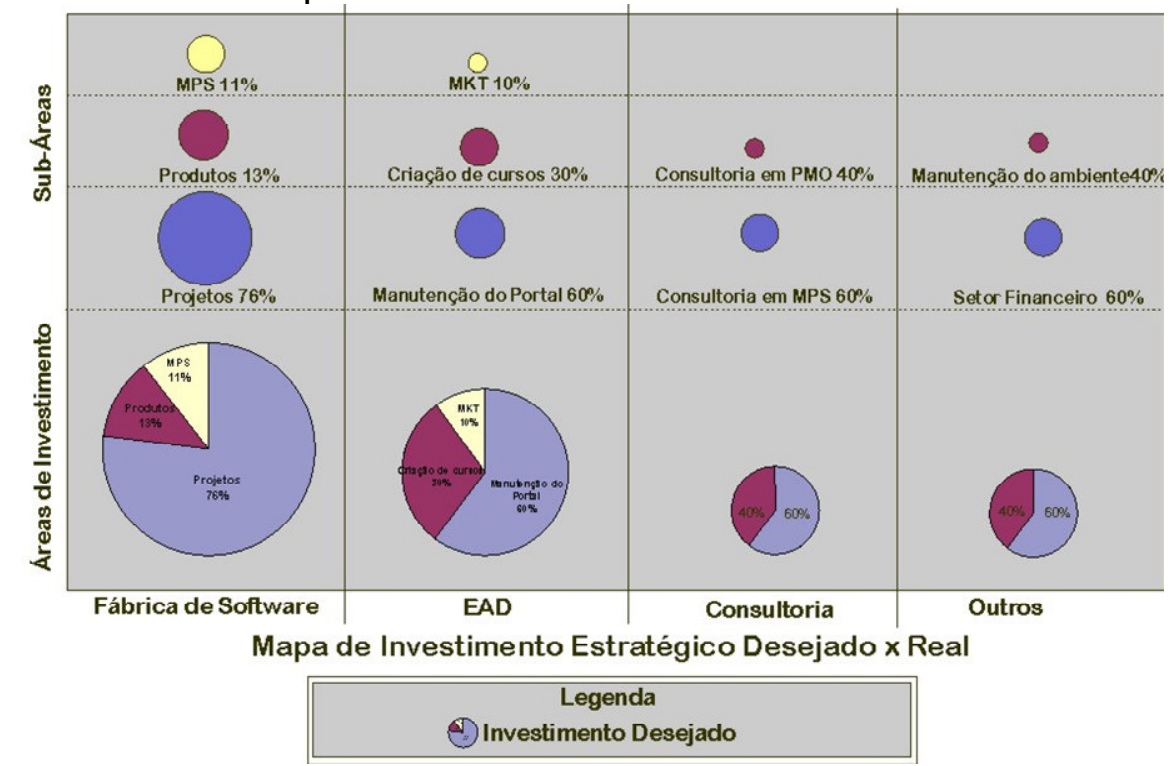

Figura 4 - Mapa de investimento desejado por área e subárea

- Atividade 2: Registrar objetivos e metas estratégicas

O principal objetivo desta atividade é o registro dos objetivos e seu desdobramento em metas estratégicas de curto, médio e longo prazo. Essas metas são registradas neste subprocesso e serão, posteriormente,

\footnotetext{
${ }^{1}$ Scorecard representa um conjunto de categorias, compostas de um conjunto de critérios, com pesos, que são utilizados para a avaliação dos projetos. Cada critério de avaliação ou benefício padrão será avaliado e multiplicado pelo seu peso, fornecendo assim uma pontuação final para os projetos.

${ }^{2}$ Gráfico utilizado para seleção de oportunidades na fase Selecionar projetos (Decisões táticas de portfólio)
} 
utilizadas para classificar os projetos como investimentos de curto, médio e longo prazo, no subprocesso "Identificar e categorizar projetos".

- Atividade 3: Registrar categorias e benefícios padrão / parametrizar SC's e indicadores

O principal objetivo desta atividade é identificar categorias de benefícios, benefícios padrão e parametrizar os Score Cards (SCs) dos benefícios padrão e riscos dos projetos candidatos a compor o portfólio da organização. Um dos critérios utilizados para seleção dos projetos é sua pontuação, segundo as categorias de benefícios padrão. Dessa maneira, projetos com maior pontuação tendem a ser selecionados frente a projetos com baixa pontuação. Para manter um padrão para as avaliações dos projetos candidatos a compor o portfólio os executivos da empresa devem indicar, dentre um conjunto de possíveis categorias, um conjunto de benefícios padrão. Os benefícios padrão definidos neste subprocesso, serão utilizados para pontuar todos os projetos candidatos. A definição de benefícios padrão visa à eliminação do viés presente nas avaliações, fornecendo critérios claros para a classificação do projeto dentro da organização, garantindo assim uma avaliação justa para todos os projetos candidatos a compor o portfólio.

Os benefícios padrão, depois de selecionados, recebem um peso, que corresponde à parametrização do $\mathrm{SC}$ de benefícios padrão e será utilizado como fator multiplicador no subprocesso "Selecionar projetos (Decisões táticas de portfólio)", onde o gerente de portfólio atribuirá uma nota a cada benefício padrão. Além dos benefícios padrão, os executivos devem parametrizar o SC de riscos dos projetos. Os riscos avaliados, nesse caso, são os riscos relacionados ao alcance dos benefícios padrão dos projetos e que serão mensurados de acordo com a pontuação atribuída pelo gerente de portfólio.

- Atividade 4: Parametrizar gráfico de benefícios padrão x riscos

A função desta atividade é parametrizar os quadrantes, indicando quais pontuações os benefícios e riscos devem ocupar nos quadrantes descritos a seguir. Conforme já destacado, um dos critérios para seleção dos projetos do portfólio é a nota do projeto, atribuída pela avaliação dos benefícios padrão esperados e da nota atribuída aos riscos de alcance dos benefícios. Após a atribuição dessas notas, os projetos são exibidos em um gráfico com 4 quadrantes com significados distintos: (i) bom para prosseguir, (ii) mitigar riscos, (iii) agregar benefícios, (iv) repensar, conforme pode ser visto na Figura 5.

\section{- Segundo Subprocesso: "Identificar e categorizar projetos"}

O subprocesso "Identificar e categorizar projetos" tem o propósito de coletar informações sobre os projetos para facilitar a sua categorização em alguma área de investimento, facilitando sua avaliação nos processos posteriores. Os principais objetivos deste subprocesso são: (i) categorizar projeto (projeto, 
programa ou atividade operacional) e sua área de negócio; (ii) descrever o projeto e seus principais objetivos e (iii) estimar em alto nível o custo, esforço e os recursos necessários para desenvolvimento do projeto. Para isso o subprocesso foi dividido em atividades que visam à obtenção dos objetivos citados as quais são descritas a seguir.

- Atividade 1: Identificar projeto

O principal objetivo desta atividade é reunir informações básicas do projeto, tais como: uma descrição sucinta do problema que se objetiva resolver, a quem afeta a solução, o impacto da execução desse projeto na organização, os benefícios esperados, um título para o projeto, um identificador e um gerente responsável por prosseguir com o trabalho.

\section{- Atividade 2: Categorizar projeto}

Os principais objetivos desta atividade são: (i) categorizar o projeto segundo as áreas e subáreas de investimentos cadastradas no subprocesso anterior de forma que esta categorização seja utilizada para balanceamento dos projetos selecionados; (ii) relacionar o projeto aos objetivos e metas para que este relacionamento seja utilizado como um dos critérios de seleção e posteriormente alimente os relatórios de alcance das metas para a alta direção da organização.

\section{- Atividade 3: Refinar descrição do projeto}

O principal objetivo desta atividade é refinar as informações que facilitarão a aprovação dos projetos que forem selecionados. Para isto, nesta atividade deve-se: (i) refinar a descrição do projeto fornecendo uma visão geral sobre ele; (ii) identificar em alto nível os objetivos do projeto; (iii) estimar em alto nível o esforço e cronograma requerido para a execução do projeto; (iv) estimar em alto nível o orçamento requerido para execução do projeto e (v) estimar os recursos requeridos para a execução do projeto.

\section{- Terceiro Subprocesso: "Selecionar projetos (Decisões táticas de portfólio)"}

O propósito deste subprocesso é selecionar os projetos alinhados para a organização (maior retorno e menor risco) pela pontuação dos critérios de seleção (benefícios-padrão e riscos) e balancear o portfólio com o mapa de investimento desejado. Assim como no subprocesso anterior, este será executado sempre que surgir um novo projeto candidato para compor o portfólio da empresa. Seus principais objetivos são: (i) classificar os projetos segundo os seus benefícios por áreas de investimento, utilizando SC (avaliação); (ii) classificar projetos segundo os riscos de atingir os benefícios esperados, utilizando SC (avaliação); (iii) selecionar projetos alinhados para a atividade de balanceamento; (iv) balancear investimentos por áreas, subáreas de negócios e realizar simulações (análise de cenários) de investimentos; e (v) 
aprovar projetos alinhados e balanceados para o pipeline ${ }^{3}$. Este subprocesso foi dividido nas seguintes atividades:

- Atividade 1: Atribuir valores aos benefícios

O principal objetivo desta atividade é pontuar os benefícios padrão e, se necessário, identificar novos benefícios específicos do projeto avaliado. Com base na pontuação atribuída pelo gerente de portfólio, o SC calcula o valor do projeto e exibe uma classificação dele em relação aos demais projetos candidatos a compor o portfólio. O SC gera, também, um conjunto de indicadores que representam a média ponderada dos benefícios de determinada categoria de benefícios. Esses indicadores representam a linha base dos benefícios padrão.

Baseado em projetos anteriores é, também, gerada uma média histórica dos indicadores de benefícios padrão que serão usados para apoiar a seleção dos projetos, conforme mostrado na parte inferior da Figura 5. Projetos com indicadores abaixo da média histórica ou do valor mínimo permitido devem ser revistos ou eliminados. Ao final dessa atividade tem-se um peso atribuído ao projeto com soma ponderada de seus indicadores e a informação se o projeto deve ou não prosseguir para a próxima atividade.

- Atividade 2: Analisar os riscos relacionados ao alcance dos benefícios dos projetos

O principal objetivo desta atividade é estimar a probabilidade e o impacto de o risco do projeto não atingir os benefícios padrão identificados na atividade anterior. Com base na pontuação atribuída pelo gerente de portfólio, a exposição aos riscos do projeto é calculada com o SC e é exibida uma classificação do projeto quanto aos riscos em relação aos demais projetos candidatos a compor o portfólio.

- Atividade 3: Avaliar / Selecionar projetos alinhados

O principal objetivo desta atividade é selecionar os projetos com alta pontuação e baixo risco. Para apoiar essa decisão são utilizados os gráficos exibidos na Figura 5.

Os quadrantes da Figura 5 indicam as decisões que devem ser tomadas se o projeto se encontrar em um deles:

- Agregar Benefícios: projetos que possuem baixo valor para os benefícios padrão e baixo risco de insucesso e que, portanto, precisam agregar mais benefícios para que possam prosseguir para os próximos subprocessos;

\footnotetext{
${ }^{3}$ Pipeline é o conjunto de projetos em execução dentro do portfólio de projetos da empresa.
} 
- Repensar: projetos que possuem baixo valor para os benefícios padrão e alto risco de insucesso devendo ser repensados ou descartados;

- Mitigar Riscos: projetos que possuem alto valor para os benefícios padrão e alto risco de insucesso devendo ter os riscos de insucesso tratados para que se desloquem para o quadrante de baixo e possam, com isso, prosseguir com a execução dos subprocessos seguintes;

- Bom para prosseguir: projetos que apresentaram alto valor para os benefícios padrão e baixo risco de insucesso devendo ser selecionados para o próximo subprocesso ("Balanceamento dos investimentos");

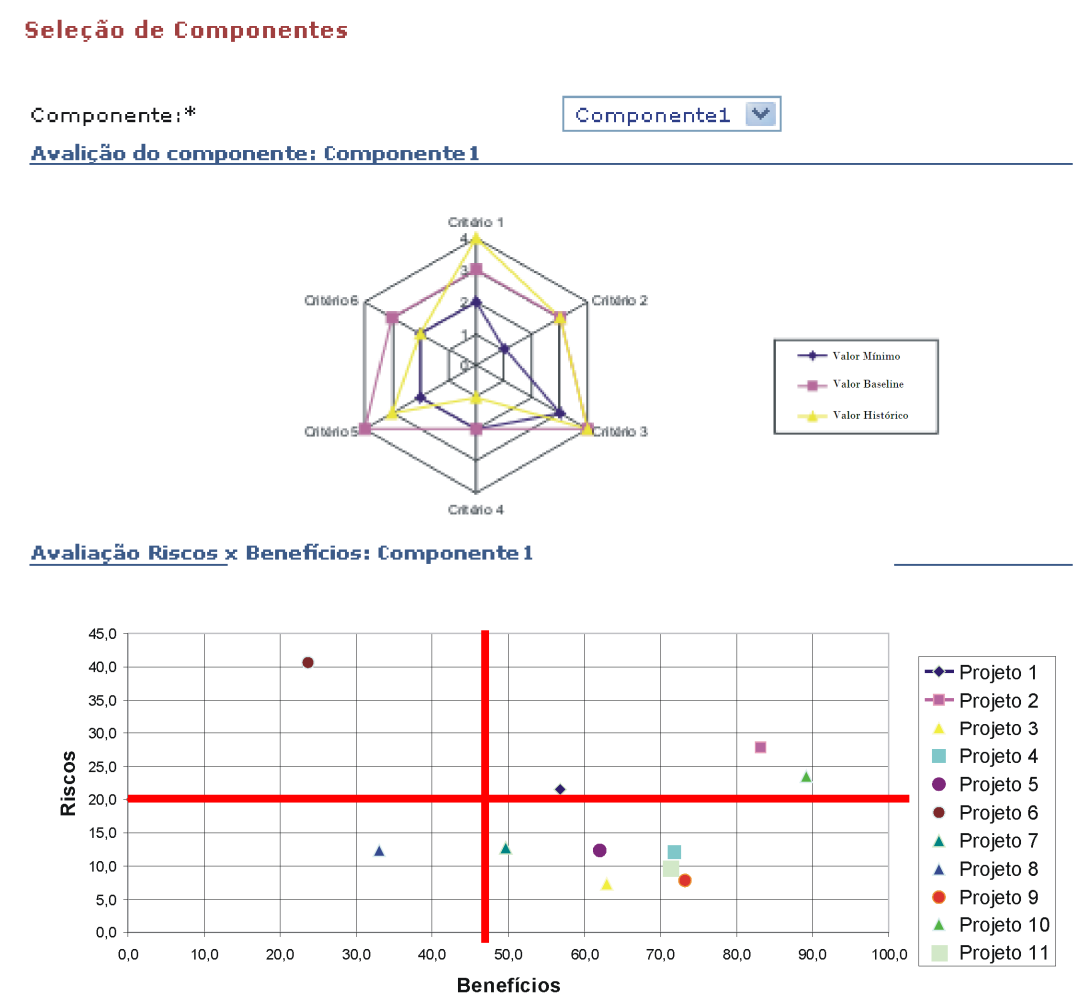

Justificar Ação

Justificativa pela Ação:*

Figura 5 - Benefícios x Riscos e gráfico de radar

- Atividade 4: Balancear investimentos e analisar cenários

O principal objetivo dessa atividade é decidir se o projeto deve ser aprovado ou postergado, baseando-se no balanceamento dos projetos, visto pela sobreposição do mapa de investimento estratégico desejado e o mapa de investimento estratégico atual. A Figura 6 mostra o 
balanceamento do portfólio e análise de cenário utilizando gráfico de bolhas. Os projetos selecionados nos subprocessos anteriores podem ser atribuídos ao mapa de investimento atual, simulando o cenário de sua aprovação e mostrando como o mapa de investimento atual ficaria se tal projeto fosse aprovado.

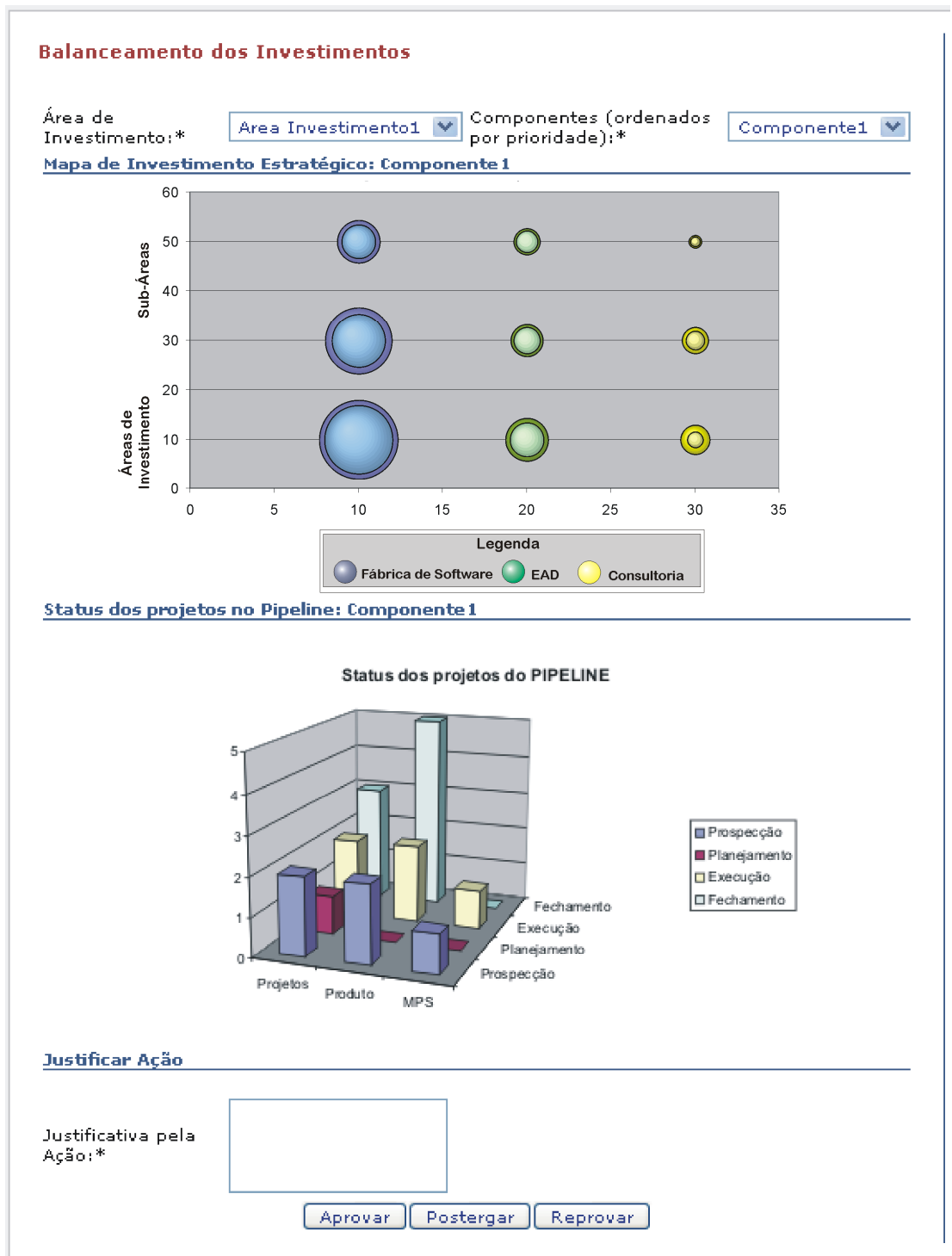

Figura 6 - Balanceamento Estratégico e Análise de cenário E SE utilizando gráfico de bolhas,

Conforme descrito no inicio dessa seção, os outros dois subprocessos serão brevemente descritos:

\section{- Quarto Subprocesso: "Manter Pipeline”}

O propósito deste subprocesso é gerenciar os projetos da organização, segundo os critérios que justificaram sua aprovação (benefícios e riscos), e monitorar os indicadores de sucesso dos projetos com uma visão consolidada do portfólio da 
organização. Depois de aprovado no subprocesso anterior, cada projeto é autorizado a iniciar sua execução com a disponibilização de recursos para tal. A execução dos projetos deve ser acompanhada por revisões periódicas dos critérios que justificaram sua aprovação, a fim de que os critérios estabelecidos sejam mantidos. Este subprocesso foi dividido nas seguintes atividades:

- Atividade 1: Monitorar Benefícios, Riscos e Metas Organizacionais:

O objetivo dessa atividade é monitorar os benefícios, riscos e metas organizacionais que sustentaram a aprovação dos projetos, tomando ações corretivas sempre que eles se desviarem do esperado ou promovendo o rebalanceamento e realinhamento, se necessário. Para isso, os gerentes dos projetos da organização precisarão reavaliá-los periodicamente, atualizando seus benefícios-padrão e riscos. Serão tomadas as ações corretivas com base nos desvios encontrados.

- Atividade 2: Monitorar Indicadores de Sucesso dos Projetos

O propósito dessa atividade é acompanhar o desempenho dos indicadores de sucesso dos projetos, a fim de encontrar desvios entre os limites estabelecidos no subprocesso "Estabelecer Gerência Estratégica de Portfólio" e os valores atuais. Os desvios encontrados deverão ser corrigidos com a definição de ações corretivas, as quais deverão ser acompanhadas até o seu fechamento.

\section{- Quinto Subprocesso: "Encerrar ou cancelar projeto"}

O propósito deste subprocesso é registrar os dados de entrega dos benefícios dos projetos que foram executados dentro da organização, tais como o percentual de alcance de metas e objetivos, além das lições aprendidas. Este subprocesso deve apoiar a atualização do planejamento estratégico, apontando a necessidade de novas iniciativas para o alcance de determinados objetivos e metas organizacionais que não foram alcançados pela execução dos projetos. Este subprocesso foi dividido na seguinte atividade:

\section{- Atividade 1: Encerrar ou Cancelar Projetos}

O propósito dessa atividade é finalizar a execução dos projetos, fornecendo retorno sobre o alcance das metas e objetivos que ele se propôs a alcançar, além do registro de lições aprendidas.

\section{Conclusão}

Para que um processo de gerência de portfólio seja aplicado em uma organização ele deve estruturar os projetos de maneira a agrupá-los, fornecendo uma visão holística. O uso de ferramentas é necessário para permitir uma visão holística e dinâmica do portfólio, possibilitando sua contínua reavaliação e fornecendo aos tomadores de decisão informações sobre o que fazer com os projetos: se devem receber mais recursos, se devem ser encerrados, atrasados ou adiantados com a realocação de recursos (MCDONOUGH III, 2003). 
Este artigo descreveu um processo para gerência estratégica de portfólio. Com base neste processo foi desenvolvido um ferramental de apoio, que foi integrado à Estação Taba. $\mathrm{O}$ processo e seu ferramental de apoio foram utilizados em uma empresa de médio porte, com o objetivo de se ter uma primeira avaliação de sua utilidade e viabilidade de uso. Sua utilização indicou a necessidade de rever os investimentos em determinados projetos, devido a baixa pontuação deles, e em alguns casos indicou o cancelamento de certos projetos que apresentaram riscos acima dos que a empresa considerava toleráveis. Essa experiência inicial permitiu a definição de parâmetros iniciais para a avaliação de benefícios e riscos dos projetos e deixou mais claro para toda a organização quais os objetivos, metas e como cada um dos projetos contribuem para seu alcance. Com os resultados desta experiência inicial de utilização, o processo e o ferramental de apoio estão sendo revistos e refinados.

Dentre as principais contribuições deste trabalho estão:

- Definição de um processo para gerência de portfólio, com as atividades que devem ser seguidas para definir a governança do portfólio, a avaliação, priorização e aprovação dos projetos, do balanceamento do portfólio e manutenção dos projetos alinhados e do portfólio balanceado;

- Definição e implementação de um apoio ferramental para auxiliar as organizações na definição das regras de governança do portfólio, da seleção, priorização e aprovação de projetos alinhados à estratégia organizacional e do balanceamento do portfólio.

Dentre os benefícios com a utilização da abordagem pode-se destacar:

- O apoio para a definição do planejamento estratégico da organização, com a definição dos objetivos e metas;

- O apoio na definição de um mapa de investimento estratégico desejado, com a definição de áreas e subáreas de investimento e seus respectivos percentuais de investimento desejados;

- O apoio na definição de critérios de avaliação dos projetos que minimizam o viés presente nas avaliações, por meio do uso de categorias de benefícios-padrão com peso mínimo necessário para a aprovação dos projetos e benefícios padrão com pesos definidos pelos executivos da empresa;

- O apoio à operacionalização do planejamento estratégico com a avaliação dos benefícios e riscos dos projetos candidatos a compor o portfólio, de sua análise e priorização utilizando o gráfico de benefícios $\mathrm{x}$ riscos e gráfico de radar;

- O apoio ao balanceamento do portfólio com a simulação de aprovação de determinados projetos e análise do mapa e de investimento estratégico desejado e mapa de investimento estratégico atual;

- E, finalmente, a maximização dos benefícios oriundos da execução dos projetos e a minimização dos riscos. 
Dentre as perspectivas futuras está a utilização da abordagem por mais empresas que desejam fazer a gerência estratégica de portfólio, permitindo uma melhor avaliação da eficácia da abordagem e sua melhoria contínua. Outras perspectivas futuras para a abordagem são:

- A implementação de um apoio ferramental para os demais subprocessos do processo ("Manter pipeline" e "Encerrar ou cancelar projetos");

- A implementação de outras dimensões para o gráfico de benefícios e riscos, com bolhas na posição dos pontos, indicando a lucratividade, custos e recursos dos projetos candidatos;

- A elaboração de indicadores de acompanhamento dos objetivos segundo o BSC (KAPLAN, 1992);

- O mapeamento dos objetivos de negócio para objetivos de TI, segundo o COBIT (IT GOVERNANCE INSTITUTE, 2000);

\section{Referências}

COOPER, R.G., S.J. EDGETT, AND E.J. KLEINSCHMIDT, 1998, "Best practices for managing R\&D portfolios", Research Technology Management, v. 41(4), pp. 20.

COOPER, R.G., S.J. EDGETT, AND E.J. KLEINSCHMIDT, 2000, "New problems, new solutions: Making portfolio management more effective", Research Technology Management, v. 43(2), pp. 18.

CRAWFORD, F GRAY \& ERIK W. LARSON, Project Management - The Managerial Process, second edition, New York, McGraw-Hill, 2002

CRAWFORD, J. K. The Strategic Project Office: A Guide to Improving Organizational Performance, New York: Marcel Dekker, Inc, 2002.

IT GOVERNANCE INSTITUTE. COBIT 3rd Edition Audit Guidelines. Disponível em http://www.isaca.org. Acessado em nov. 2008

KAPLAN, R.S.A.N., D. P., 1992, "The Balanced Score Card - Measures that Drive Performance", Harvard Business Review.

KERZNER, H. Strategic Planning for a Project Office. Project Management Journal, v. 34, n. 2, p.13-25, 2005.

MCDONOUGH III, E.F.A.F.C.S., 2003, "Managing project portfolios", Research Technology Management, v. 46(3), pp. 40.

MONTONI, M., SANTOS, G., ROCHA, A.R., et al. (2007), "MPS Model and TABA Workstation: Implementing Software Process Improvement Initiatives in Small Settings". In: Fifth Workshop on Software Quality held in conjunction with the 29th Int. Conference on Software Engineering (ICSE), Minneapolis, USA, May.

N. ARCHER, F.G., 1999, "An integrated framework for project portfolio selection", International Journal of Project Management, v. 17, pp. 207 216. 
NBR-ISO1006, 2000, "Gestão da qualidade - Diretrizes para a qualidade no gerenciamento de Projetos", ABNT Associação Brasileira de Normas Técnicas, pp. 1 - 18.

PMI, 2006a, The Standard for Portfolio Management, First Edition, Newtown Square, Pennsylvania, Project Management Institute - PMI.

PMI, 2006b, The Standard for Program Management, First Edition, Newton Square, Pennsylvania, Project Management Institute - PMI.

PMI, 2004, PMBOK - A Guide to the Project Management Body of Knowledge, Third Edition, Newtown Square, Pennsylvania, Project Management Institute - PMI.

SEI, S.E.I., 2006, "CMMI® for Development (CMMI-DEV), V1.2, CMU/SEI2006-TR-008", Software Engineering Institute.

SOFTEX, 2007, "MPS.BR - Melhoria de Processo do Software Brasileiro, Guia Geral", v. v1.2.

SRIVANNABOON, S., 2006, "Linking Project Management with business strategy". In: PMI Global Congress Proceedings, Seattle Washington.

YELIN, K.C., 2007, Linking strategy and Project Portfolio Management, In Project Portfolio Management: A practical guide to selecting projects, managing portfolios and maximizing benefits, first edition, San Francisco, Jossey-Bass. 